\title{
DEBATES
}

\section{Destinos Cruzados: Partidos e Candidatos nas Eleições para Prefeito no Brasil e Intendente no Uruguai (2000-2012)}

\author{
Crossed Destinies: Parties and Candidates in Elections for Mayor in \\ Brazil and Uruguay (2000-2012)
}

\section{Alvaro Augusto de Borba Barreto}

\section{Resumo}

Neste trabalho, compara-se a capacidade que os partidos políticos do Brasil e do Uruguai tiveram de se manter no poder (reeleger-se) nas eleiçôes para chefe dos executivos subnacionais (chamados, respectivamente, de prefeito e de intendente) realizadas no período compreendido pelos anos 2000 e 2012. Para isso, analisam-se quatro disputas realizadas no Brasil: 2000, 2004, 2008 e 2012, nos 62 principais municípios; e três realizadas no Uruguai: 2000, 2005 e 2010, nos 19 departamentos. Adotase como parâmetro para dimensionar a performance dos partidos a comparação dos resultados por eles obtidos com aqueles alcançados pelos titulares dos cargos. Desse modo, surgem três situaçóes: 1) quando os partidos contam com o titular do cargo que concorre à reeleição imediata (incumbent); 2) quando este não participa da disputa; 3) quando os resultados do partido e do incumbent podem ser diferentes, qual seja, eles são concorrentes ou é possível dissociar o desempenho de um e de outro.

\section{Palavras-chave}

Eleições Subnacionais; Reeleição; Partidos; Brasil; Uruguai.

\begin{abstract}
This paper compares the political parties' capacity to be re-elected for mayor in Brazil and Uruguay from 2000 to 2012. Four elections are analyzed in Brazil (2000, 2004, 2008 and 2012) in 62 of the principal municipalities, and three elections in Uruguay (2000, 2005 and 2010) in 19 counties. The parameter utilized to evaluate political parties' performance is achieved through the comparison of the results obtained by the executives in power. In this way, three situations emerge: 1) when parties rely on the executive in power that is seeking reelection (incumbent); 2) when the incumbent does not participate of the electoral race; 3 ) when the results of the party and the incumbent could be different, that is, they are competitors or it is possible to dissociate each other's performance.
\end{abstract}

\section{Keywords}

Subnational Elections; Reelection; Parties; Brazil; Uruguay. 


\section{Introdução}

O artigo versa sobre as eleições para prefeito no Brasil e para intendente no Uruguai, no período 2000-2012, e dá continuidade a investigaçóes precedentes (BARRETO, 2010, 2012a, 2012b). É importante destacar que essas autoridades comandam o poder executivo de âmbito local de seus países: o primeiro atua nos municípios, um dos três entes da federação brasileira, ao lado dos estados e da União; e o segundo, nos departamentos, nível subnacional da organização estatal uruguaia ${ }^{\text {. }}$

O mote para a escolha desse objeto de estudo é o fato de, no final da década de 1990, os dois países terem modificado as normas que disciplinam a escolha desses chefes do executivo. Duas novidades em especial reduziram as diferenças institucionais até então existentes, tornaram esses processos políticos mais semelhantes e ampliaram as perspectivas de realização de uma análise comparada dotada de maior razoabilidade.

Presente na ampla reforma constitucional promulgada em janeiro de 1997 pelo Uruguai, a primeira inovação determinou que os intendentes (e os membros dos legislativos departamentais) passassem a ser escolhidos em um pleito realizado cerca de sete meses após as eleiçôes para presidente, senadores e deputados ${ }^{2}$. Antes, as disputas departamental e nacional eram não só simultâneas no tempo como politicamente vinculadas ${ }^{3}$. O Brasil, por sua vez, separa os pleitos municipais das

\footnotetext{
${ }^{1}$ A partir de 2010, o Uruguai implantou um terceiro nível de administração, chamado município, que tem o alcalde como chefe do executivo. Ressalva-se que a autonomia político-administrativa dos municípios brasileiros é muito mais ampla do que aquela dos recém criados no Uruguai, de modo a não existir plena correspondência entre as estruturas estatais homônimas. Para mais detalhes, ver: Oroño (2010) e Barreto (2011).

${ }^{2}$ A escolha do legislativo nacional e o $1^{\mathrm{o}}$ turno das eleiçôes presidenciais ocorrem em outubro e a eleição departamental (e, a partir de 2010, a municipal), em maio do ano seguinte. Quando é necessária a realização de $2^{\circ}$ turno para presidente, esta acontece em novembro.

${ }^{3} \mathrm{O}$ sistema uruguaio exige que, para todos os cargos em disputa em uma determinada eleição, o eleitor escolha nomes do mesmo partido. $\mathrm{O}$ voto que não cumprir tal requisito é anulado. A única alternativa a essa determinação é votar em branco para um ou alguns cargos. Com a separaçáo temporal das disputas, a vinculação ficou restrita aos postos nacionais (presidente, senadores e deputados) ou aos subnacionais (intendente, edil departamental e, desde 2010, autoridade municipal). Conforme Guerrini (2000) e Cardarello (2001), a simultaneidade e a vinculação criava um efeito de arrasto da eleição presidencial sobre a local, em razão da centralidade daquela disputa, logo, quase sempre a sorte do intendente ficava associada ao desempenho dos candidatos presidenciais de seu partido, independentemente da qualidade da gestão ou dos níveis de aprovação que ele apresentava. Os dados trazidos por López (2007) indicam que nos pleitos de 1984, 1989 e 1994, os três maiores partidos obtiveram, em cada departamento, diferenças absolutas de votos entre as eleiçóes nacionais e as departamentais de $0,7 \%$ em média.
} 
demais instâncias há muitas décadas e, no atual calendário eleitoral, que vem sendo aplicado desde 1994, dois anos após a escolha do presidente, dos governadores e dos respectivos legislativos federal e estadual, são definidos os prefeitos e os vereadores (membros dos legislativos locais).

A segunda medida, estabelecida pelo Brasil por meio da Emenda Constitucional 16 ao texto de 1988, de quatro de junho de 1997, autorizou todos os chefes do poder executivo (presidente, governador e prefeito) a concorrerem a mais um único mandato sucessivo, instituto que estava à disposição dos intendentes uruguaios desde 1934. Logo, ao ser implantada a reeleição era uma prática seguida pelo país vizinho em escala subnacional há mais de seis décadas ${ }^{4}$.

Em resumo, prefeitos e intendentes passaram a ser escolhidos conforme um calendário eleitoral exclusivo, sendo facultada aos titulares a possibilidade de pleitear a recondução imediata. Coincidentemente, no âmbito subnacional dos países, as novas regras foram aplicadas pela primeira vez no mesmo ano: no Uruguai, em maio de 2000, e no Brasil, em outubro5.

Tendo em vista essas aproximaçóes, o propósito deste trabalho é analisar os efeitos que elas produziram desde que foram implantadas. De um lado, procura verificar se o fenômeno da reeleição imediata dos chefes do executivo em disputas isoladas se apresenta de modo semelhante ou não nos dois países; de outro, quer identificar e dimensionar as eventuais diferenças entre os resultados. A investigação é realizada em torno do titular do executivo que se reapresenta em busca de um novo mandato sucessivo ou imediato - identificado genericamente como incumbent ${ }^{6}$ - e do partido que, tendo elegido o prefeito ou o intendente no pleito anterior, procura preservar o cargo e/ou manter-se no poder na eleição subsequente.

Foram acompanhadas quatro disputas no Brasil (2000, 2004, 2008 e 2012); e três no Uruguai (2000, 2005 e 2010). Elas correspondem a todas aquelas realizadas em âmbito subnacional depois da adoção das mudanças institucionais a que se fez referência. Já que o foco está voltado à reeleição, tornou-se necessário considerar também os pleitos imediatamente anteriores a esses, ou seja, o brasileiro de 1996 e o uruguaio de 1994.

\footnotetext{
${ }^{4}$ Ao Presidente uruguaio sempre foi - e continua a ser - negado o direito de reeleição imediata. O alcalde pode disputar a reeleição imediata, no entanto, como os primeiros titulares tomaram posse em 2010 tal prerrogativa ainda não foi utilizada.

${ }^{5}$ Em 1998, o presidente e os governadores brasileiros usufruíram de tal prerrogativa.

${ }^{6}$ Em português e em espanhol não há um termo específico para indicar essa situação, razão pela qual se optou por utilizar a palavra inglesa.
} 
A decisão de comparar os intendentes uruguaios e os prefeitos brasileiros decorre do tipo de atividade administrativa por eles exercida e do papel político que desempenham na estrutura de cada país. O departamento uruguaio abrange uma cidade (a capital departamental) e diversas vilas ou povoados, o que aparentemente o torna mais parecido com um estado brasileiro, porém, a administração apresenta uma complexidade e exige uma demanda de tarefas mais semelhantes as dos municípios, muito em razão do restrito contingente populacional: com exceção de Montevidéu, Canelones e Maldonado, nenhum possui mais de 150 mil habitantes (INE-UY, 2014). Por outro lado, apesar de serem autoridades políticas que no conjunto abarcam a totalidade do território do país, o que os aproxima mais dos governadores do que dos prefeitos brasileiros, a estrutura unitária do Estado uruguaio faz com que os intendentes atuem prioritariamente no âmbito local e tenham pouca atuação na proposição e na definição de políticas nacionais, papel este reservado à Assembleia Geral, o legislativo uruguaio. Nessa linha, Buquet, Chasquetti e Moraes (1998) indicam que o intendente é uma autoridade executiva local, cujos poderes, atribuições e funçóes são mais parecidos com as de um prefeito do que de um governador. Mesmo Cardarello (2009), que optou em seu estudo por aproximar o intendente ao governador, aponta que ele é uma figura mista, pois está a meio caminho de ser o governador do departamento e o prefeito da capital departamental ${ }^{7}$.

No entanto, a comparação proposta envolve um problema de escala. As grandezas entre os países são muito díspares - o Brasil possui mais de 5 mil prefeitos e o Uruguai, 19 intendentes -, razão pela qual se delimitou os casos analisados à totalidade das unidades subnacionais uruguaias ${ }^{8}$ e a 62 dos mais importantes municípios brasileiros (as 26 capitais estaduais e os 36 que, desde 2000, poderiam realizar eleições em dois turnos por contarem com mais de 200 mil eleitores ${ }^{9}$ ).

\footnotetext{
${ }^{7}$ A respeito dos papéis administrativos e políticos desempenhados pelos intendentes uruguaios ao longo do tempo, bem como as recentes transformaçôes que eles sofreram (de "bom vizinho" a “empreendedor”), ver em Laurnaga e Guerrini (1994) e Guerrini (2000).

8 Artigas, Canelones, Cerro Largo, Colonia, Durazno, Flores, Florida, Lavalleja, Maldonado, Montevideo, Paysandú, Río Negro, Rivera, Rocha, Salto, San José, Soriano, Tacuarembó, Treinta y Tres.

${ }^{9}$ Belford Roxo, Campina Grande, Campinas, Campos, Canoas, Caxias do Sul, Contagem, Diadema, Duque de Caxias, Feira de Santana, Guarulhos, Jaboatão, Joinville, Juiz de Fora, Jundiaí, Londrina, Maringá, Mauá, Mogi das Cruzes, Niterói, Nova Iguaçu, Olinda, Osasco, Pelotas, Piracicaba, Ribeirão Preto, Santo André, Santos, São Bernardo do Campo, São Gonçalo, São João de Miriti, São José do Rio Preto, São José dos Campos, Sorocaba, Uberlândia e Vila Velha. Com vistas a manter o mesmo universo ao longo do período, não foram incluídos os dez municípios que atingiram 200 mil eleitores em 2004: São Vicente, Bauru, Carapicuíba, Petrópolis, Cariacica, Serra, Montes Claros, Anápolis,
} 
Embora esse conjunto corresponda a 1,1\% dos 5.568 municípios do Brasil, abrange $32,8 \%$ do eleitorado nacional apto a participar de pleitos locais, conforme dados de 2012 (RODRIGUES, 2012). Assim, foram acompanhados os mesmos casos ao longo do período, em um total de 305 disputas (248 no Brasil e 57 no Uruguai).

No que tange ao Uruguai, a identificação dos candidatos e dos partidos, da situação em que se encontravam, bem como dos resultados eleitorais por eles obtidos, baseou-se: 1) nas obras que versaram sobre os ciclos de 1999-2000 e de 2004-2005, organizadas pelo Instituto de Ciência Política da Universidade da República (VÁRIOS AUTORES, 2000; BUQUET, 2005a); 2) nos dados relativos ao pleito de 2010 consultados diretamente no site da Corte Eleitoral do país. Para o Brasil, a fonte principal foi o site do Tribunal Superior Eleitoral (TSE), consultado para obter as informações relativas aos titulares dos cargos (inelegibilidade e reapresentação), composição das coligações (se elas ocorreram) e, finalmente, resultados eleitorais. No entanto, persistiram dúvidas em relação aos que não participaram do pleito: não se sabia se haviam desistido, tido a candidatura impugnada pela Justiça Eleitoral ou sido substituídos (em razão de renúncia, afastamento pela Justiça, falecimento), pois a pesquisa trabalhou com a perspectiva de considerar mudanças na relação de titulares do cargo. Nessa situação, tornou-se imprescindível analisar as circunstâncias de cada caso para classificar ou não o sucessor como prefeito e, em caso positivo, identificar o partido a que estava filiado, a eventual condição de candidato a continuar no cargo, ou seja, de incumbent. Essa rede de informaçóes implicou a consulta a artigos e a diversos sites: institucionais (prefeituras, sobretudo), de alguns políticos e de órgáo de imprensa.

A exposição está montada em torno de três seções: a primeira foca as informações relativas aos incumbents: quantos poderiam concorrer, quantos de fato de apresentaram e o resultado que obtiveram; a seção seguinte aborda os partidos políticos; e a terceira cruza os dados relativos aos dois atores, com vistas a verificar e consolidar determinadas tendências. Nas duas últimas seções também figura uma série de apontamentos referentes a decisões metodológicas e a procedimentos adotados pela pesquisa.

Aparecida de Goiânia e Ponta Grossa. Na mesma medida, não foram considerados os sete municípios que passaram a contar com a possibilidade de $2^{\circ}$ turno em 2008 (Blumenau, Uberaba, Betim, Volta Redonda, Ananindeua, Franca e Guarujá) e os seis que atingiram essa condição em 2012 (Itaquatecuba, Vitória da Conquista, Taubaté, Barueri, Cascavel e Limeira). 


\section{Resultados obtidos pelos chefes do executivo}

Como mostra a Tabela 1 , os índices apresentados pelos dois países são semelhantes no que tange aos titulares do executivo local que poderiam pleitear um novo mandato imediato (73\%, no caso do Brasil e 78,9\%, no Uruguai), a revelar que a ampla maioria deles teria condições de se tornar incumbent.

Tabela 1 - Condição dos chefes do executivo local do Brasil e do Uruguai quanto a concorrer à reeleição imediata, no período 2000-2012 (\%)

\begin{tabular}{c|c|c}
\hline Situaçáo & Brasil & Uruguai \\
\hline Elegivel & 73,0 & 78,9 \\
\hline Inelegível & 27,0 & 21,1 \\
\hline Total (N) & 248 & 57 \\
\hline
\end{tabular}

Fonte: TSE-BR, Corte Electoral-UY (2010), Vários Autores (2000) e BUQUET (2005a).

Os dados referentes ao Brasil estão superdimensionados, pois, como o pleito de 2000 foi o primeiro após a adoção da medida, todos os prefeitos podiam concorrer à reeleiçáo ${ }^{10}$. Apesar disso, a comparação com o Uruguai é válida porque, em 2000, a totalidade dos intendentes também podia pleitear a reeleição, embora lá a medida já estivesse em vigor há muito mais tempo. Ocorre que todos aqueles que se tornariam inelegíveis porque estavam no exercício do segundo período consecutivo foram substituídos ao longo do mandato, em razão de renúncia ou de morte.

Tabela 2 - Decisão dos chefes do executivo local do Brasil e do Uruguai quanto a concorrer à reeleição, no período 2000-2012 (\%)

\begin{tabular}{c|c|c}
\hline Situação & Brasil & Uruguai \\
\hline Concorreram & 81,8 & 80,0 \\
\hline Náo concorreram & 17,5 & 20,0 \\
\hline Total $(\mathrm{N})$ & 181 & 45 \\
\hline
\end{tabular}

Fonte: TSE-BR, Corte Electoral-UY (2010), Vários Autores (2000) e Buquet (2005a).

A Tabela 2 indica que dentre os prefeitos e os intendentes que poderiam pleitear um segundo período consecutivo - seja porque foram estavam no exercício do primeiro mandato, seja porque foram empossados de modo definitivo em substituição a quem havia sido originalmente eleito - é muito elevado o contingente daqueles que efetivaram tal prerrogativa. Ou seja, dentre aqueles que tinham condições de se tornar incumbent, no mínimo $80 \%$ efetivaram tal condição. E,

\footnotetext{
${ }^{10}$ Se forem consideradas apenas as disputas de 2004, 2008 e 2012, quando impedimentos oriundos do exercício de um segundo mandato consecutivo passaram a operar, o índice cai para 64\%.
} 
novamente, não há variação significativa entre os dois países, pois o índice é de $80 \%$ no Uruguai e de $81,8 \%$ no Brasil.

Tabela 3 - Resultado obtido pelos chefes do executivo local do Brasil e do Uruguai que buscaram a reeleição, no período 2000-2012 (\%)

\begin{tabular}{c|c|c}
\hline Resultado & Brasil & Uruguai \\
\hline Vitória & 68,2 & 61,1 \\
\hline Derrota & 31,8 & 38,9 \\
\hline Total $(\mathrm{N})$ & 148 & 36 \\
\hline
\end{tabular}

Fonte: TSE-BR, Corte Electoral-UY (2010), Vários Autores (2000) e Buquet (2005a).

Os dados trazidos pela Tabela 3 mostram que a maioria dos candidatos à reeleiçáo imediata obteve sucesso, tanto em um país quanto no outro. Parece prevalecer o argumento de Cardarello (2009): o chefe do executivo tem várias vantagens estratégicas na competiçáo frente aos demais. A primeira e mais óbvia delas, o fato de já estar no cargo, seguindo-se: ser um nome provavelmente mais conhecido do que os outros concorrentes, contar com maior acesso aos meios de comunicaçáo, mais facilidade para obter financiamento para a campanha, assim como recursos governamentais que podem ser usados direta ou indiretamente na eleição. Como reforço a essas vantagens, Jones (1999) demonstrou que a presença do incumbent cria uma competição do tipo plebiscitário, no qual está em julgamento a qualidade e a aceitação da gestão.

Baseado nos mesmos dados, também se pode dizer que buscar a reeleição imediata não é um investimento alheio a riscos, ao contrário, o índice geral de 33,2\% de insucesso não pode ser considerado desprezível (61 em 184 tentativas), sendo de 31,8\% no Brasil (47 em 148 situações) e de 38,9\% no Uruguai (14 em 36 casos).

Como outra face da mesma moeda, as informaçôes mostram uma diferença entre os dois países no que tange ao sucesso do incumbent. Ela não contraria a tendência geral, mas é a mais intensa dentre as informações já coletadas: o índice obtido no Brasil é cerca de $11 \%$ ou 7,1 pontos percentuais maior do que o do Uruguai $(68,2 \%$ a $61,1 \%)$.

\section{Resultados obtidos pelos partidos}

Esta seção versa sobre uma segunda personagem, os partidos políticos. Antes de apresentar os dados, no entanto, é preciso fazer uma pequena digressão, com vistas a explicitar algumas decisóes metodológicas e o modo como as informaçóes foram organizadas. 
O primeiro aspecto a destacar é que os partidos, ao contrário dos prefeitos e dos intendentes, não enfrentam o impedimento legal da inelegibilidade após o exercício do segundo mandato consecutivo. Apesar disso, os partidos dos chefes do executivo podem deixar de disputar a reeleição por fatores circunstanciais em determinados municípios, bem como em razão de extinção. No período e no conjunto de municípios/departamentos investigados náo foi registrado nenhum caso de partido que deixou de existir, mas sim um de fusão entre agremiações: em 2006, o Partido Liberal (PL), do Brasil, que conquistou prefeituras nos municípios analisados, fundiu-se ao Partido da Reedificação da Ordem Nacional (PRONA), que náo elegeu prefeito na amostra da pesquisa, o que deu origem ao Partido da República (PR). Também houve duas situações de partidos brasileiros que mudaram de denominação: o Partido Progressista Brasileiro (PPB) passou a ser identificado como Partido Progressista (PP), em 2003; e o Partido da Frente Liberal (PFL) adotou o nome de Democratas (DEM), em 2007. Em todas essas situaçóes, a legenda advinda desse processo foi considerada aquela que buscava a reeleição, razão pela qual foi possível abranger a totalidade dos pleitos analisados.

Desse modo, enquanto há 185 situaçôes com a presença do incumbent, foram identificados 305 pleitos em que um partido busca a reeleição, ou seja, a totalidade das eleições em análise. No caso brasileiro, são 248 tentativas dos partidos de se manter no poder e 148 dos prefeitos (100 a menos ou 40,3\%); no uruguaio, 57 e 36, respectivamente (21 a menos ou 36,8\%). Em tese, tais diferenças podem ser suficientes para fazer com que os resultados relativos aos partidos sejam diversos daqueles já identificados para os incumbents.

O segundo refere-se a peculiaridades do sistema político brasileiro, as quais precisam ser levadas em conta para que se possa definir com mais precisão quem é o partido que busca a reeleição imediata. A resposta parece óbvia: é aquele que conquistou o mandato no pleito anterior (no caso, o cargo de prefeito). Porém, em que medida um partido pode ser considerado vencedor na disputa anterior: somente quando ele é o do candidato vencedor ou também, quando ocorre coligação, se compóe a aliança eleitoral entre legendas pela qual este concorreu, seja ao indicar o nome do vice-prefeito, seja ao simplesmente apoiar a chapa majoritária vencedora? Como contrapartida: pode-se considerar que um partido busca a reeleição se na disputa seguinte não apresenta candidato a prefeito, mas compóe uma coligação que concorre ao pleito (ao indicar o vice ou aliar-se a outras legendas), ou é imprescindível ter candidato próprio à "cabeça" da chapa?

A situação é particularmente delicada porque o Brasil convive com dois fenômenos raramente registrados no Uruguai. O primeiro é a migração partidária, a 
situação em que, ao longo do mandato, o prefeito abandona a legenda pelo qual se elegeu, filia-se a outro e pleiteia a reeleição pelo novo partido.

O outro se refere aos casos de substituição definitiva do prefeito, a qual é acompanhada pela mudança do partido que está no poder ${ }^{11}$. Tal situação ocorre porque é comum que, em razão da coligação, o vice-prefeito seja indicado por uma legenda distinta daquela que apresentou o candidato a chefe do executivo ${ }^{12}$. Como as coligações podem ser alianças ocasionais entre os partidos que não necessariamente envolvam firmes compromissos pós-eleitorais (alternativamente, quando esses compromissos existem, eles podem perder consistência durante o exercício do mandato), algumas das mudanças de titular a que se faz referência podem implicar o rompimento do partido do prefeito eleito com o do novo governante e a consequente reconfiguração das forças no poder. Como reflexo, a legenda daquele que foi substituído e a do novo tornam-se adversárias na próxima eleição municipal.

Essas situações fizeram com que a pesquisa adotasse alguns procedimentos para classificar a condição de partido que pleiteia a reeleição imediata, os quais estão baseados na valorização prioritária da legenda que elegeu o prefeito:

1. Se este trocou de legenda ao longo do mandato, considerou que quem buscava a reeleição era o partido pelo qual ele se elegeu, e não aquele ao qual ele aderiu posteriormente. Obviamente, tal decisão se aplica sempre que o partido de filiação original apresentar ou apoiar outro candidato que não o incumbent ou aquele indicado pelo governo, na hipótese de o próprio prefeito não concorrer. Afinal, se ele mantiver o apoio, os resultados de ambos continuam atrelados, como explicita o procedimento 3, apresentado na sequência ${ }^{13}$;

2. No caso em que a substituição definitiva do chefe do executivo implicou a mudança do partido do titular, o estudo tomou a legenda daquele originalmente eleito como a que buscou a reeleição, e não a

\footnotetext{
11 As razões dessa substituição definitiva não importam no momento, mas derivam de: cassação, renúncia ou morte do titular.

12 Em condiçóes normais, na falta do prefeito, quem assume o posto é o vice. Porém, deve-se considerar que, em determinados casos (notadamente quando se trata de cassação de ordem política ou por decisão judicial), ambos podem perder o cargo, situação em que é empossado o presidente da Câmara Municipal ou, eventualmente, outros membros da Mesa diretora do legislativo local. Independentemente de quem vai assumir o cargo, o vital é considerar a situação em que o novo titular não pertence ao partido do prefeito afastado.

${ }^{13}$ Embora tenham sido registradas 34 trocas de legenda por parte dos prefeitos, 24 foram consideradas, pois em dez casos o partido abandonado apoiou o prefeito quando este se tornou incumbent ou, quando ele não concorreu, prestigiou a coligação da qual participava o novo partido.
} 
do novo prefeito. Assim como na situação anterior, se o partido que elegeu o prefeito compuser a coligação em que está o partido do novo titular do executivo (em torno dele ou de outro candidato), os destinos de ambos ficam associados e se dissipam tais diferenças ${ }^{14}$;

3. Quando o titular do executivo não concorre, a investigação avaliou que o partido que havia elegido o prefeito estaria reeleito se compusesse uma coligação vencedora, ainda que não fosse a legenda do candidato eleito para o cargo ${ }^{15}$. A razão para esta escolha decorre da percepção de que não ser o partido do novo prefeito inegavelmente retira daquela legenda a condição de protagonista que ostentava até entáo, mas não a participação no futuro governo e a continuidade no poder.

Feitos esses esclarecimentos, passa-se à apresentação dos resultados.

Tabela 4 - Resultado obtido na eleição seguinte pelo partido que havia conquistado o executivo local no Brasil e no Uruguai, no período 2000-2012 (\%)

\begin{tabular}{c|c|c}
\hline Resultado & Brasil & Uruguai \\
\hline Vitória & 50,4 & 71,9 \\
\hline Derrota & 49,6 & 28,1 \\
\hline Total (N) & 248 & 57 \\
\hline
\end{tabular}

Fonte: TSE-BR, Corte Electoral-UY (2010), Vários Autores (2000) e Buquet (2005a).

A Tabela 4 mostra que, tanto no Uruguai quanto no Brasil, o índice de reeleição imediata alcançado pelos partidos supera os 50\%. Todavia, aquele apresentado pelos partidos uruguaios é bem maior do que o dos brasileiros (em termos relativos, a diferença é de cerca de um terço ou 21,5 pontos percentuais): enquanto no primeiro país, em $71,9 \%$ dos 57 pleitos analisados o partido se manteve no poder; no segundo, isso ocorreu em 50,4\% das 248 eleiçóes.

Os resultados dos dois também eram distintos no quesito reeleição de prefeitos e de intendentes, embora as diferenças não fossem tão robustas. Entretanto, o que mais chama a atenção é o fato de os sentidos não serem convergentes: no Brasil, o incumbent consegue um êxito muito mais intenso do que os partidos $(68,2 \%$ a $50,4 \%)$, e no Uruguai prevalecem as legendas em relação aos titulares do cargo $(71,9 \%$ a $61,1 \%)$.

\footnotetext{
${ }^{14}$ Foram identificadas 24 dessas situações, mas em somente dez delas ocorreu uma futura disputa entre o partido que elegeu o antigo prefeito e o do novo, sendo que em sete havia o incumbent.

${ }^{15}$ Isso ocorreu dez vezes.
} 


\section{Cruzamento dos resultados obtidos pelos chefes do executivo e pelos partidos}

Novas perspectivas interpretativas podem surgir se forem cruzadas as duas informaçóes, isto é, se for considerado o resultado da tentativa de reeleição dos partidos, quando contam ou não com o incumbent.

Antes, é preciso lembrar que, por conta das decisões metodológicas apresentadas anteriormente, no Brasil o número de casos em que partido e incumbent concorrem juntos se reduz a 123. Isso porque, às 100 oportunidades já identificadas em que - a exemplo dos 21 casos uruguaios - o chefe do executivo não podia ou não quis pretender a reeleição, devem ser acrescidas outras 25 nas quais, apesar de existir o incumbent, ele e o partido pelo qual havia se elegido foram adversários. Desse modo, os dados apresentados não abarcam simplesmente as situaçóes em que não há o titular do cargo em busca da reeleição imediata na disputa, e sim aquelas em que o partido que elegeu o prefeito ou o intendente náo pôde contar com ele. Por fim, informa-se que esses casos atingem 36,8\% dos 57 pleitos analisados do Uruguai e 50,4\% dos 248 do Brasil.

Tabela 5 - Resultado obtido na eleição seguinte pelo partido que havia conquistado o executivo local no Brasil e no Uruguai, conforme o fato de ser ou não o do incumbent, no período $2000-2012(\%)$

\begin{tabular}{c|c|c|c|c}
\hline \multirow{2}{*}{ Partido } & \multicolumn{2}{|c|}{ Com incumbent } & \multicolumn{2}{c}{ Sem incumbent } \\
\cline { 2 - 5 } & Brasil & Uruguai & Brasil & Uruguai \\
\hline Vitória & 69,1 & 66,7 & 32,0 & 81,0 \\
\hline Derrota & 30,9 & 33,3 & 68,0 & 19,0 \\
\hline Total (N) & 123 & 36 & 125 & 21 \\
\hline
\end{tabular}

Fonte: TSE-BR, Corte Electoral-UY (2010), Vários Autores (2000) e Buquet (2005a).

Como mostra a Tabela 5, o partido que conta com o incumbent obtém resultados semelhantes nos dois países: no Brasil, o índice de reeleição é de 69,1\% (85 em 123 pleitos), e no Uruguai, de 66,7\% (24 em 36). No entanto, quando o partido não conta com o incumbent, o contraste é muito nítido: no Uruguai, ele mantém o cargo em 81\% dos casos (17 em 21) e, no Brasil, em apenas 32\% (40 em 125).

Essas informações se somam às anteriores e permitem interpretar que os partidos brasileiros dependem do incumbent muito mais do que os uruguaios ou supor que estes náo dependem da presença do incumbent para manter o cargo, como já registrou Cardarello (2009) ao se debruçar sobre informaçóes semelhantes. Tal percepção é reforçada por um detalhe significativo: no Uruguai, sempre que o partido não possui o candidato à reeleição imediata, ele alcançou índices de sucesso mais 
elevados do que quando o apresentou ( $81 \%$ a $66,7 \%)$; no Brasil, ocorre o inverso $(32 \%$ a $69,1 \%)$.

Pode-se avançar nessa questáo ao considerar mais um traço de similaridade entre os sistemas eleitorais do Brasil e do Uruguai: a possibilidade de o partido e o candidato que se elegeram juntos terem destinos distintos na eleição seguinte. No entanto, tal semelhança tem motivaçóes bem diferentes, como será indicado a seguir.

No caso do Brasil, já foram apresentadas essas situações. Elas decorrem de processos legais, mas não previstos nas regras específicas dos pleitos, e estáo calcadas no rompimento de vínculos políticos: o titular que abandona o partido pelo qual se elegeu ou a troca de titularidade do cargo que gera a ruptura na aliança vencedora do pleito. No que se refere ao Uruguai, a dissociação deriva de um princípio existente nas próprias regras que disciplinam os processos eleitorais: cada partido pode lançar até três candidatos para o cargo de intendente ${ }^{16} \mathrm{e}$, por meio do chamado "duplo voto simultâneo", é possível que o incumbent seja derrotado, mas o partido dele não, isto é, que outro candidato apresentado pela legenda venha a ser o mais votado e a ficar com o cargo ${ }^{17}$. Essa situação é impossível no caso brasileiro, visto que cada partido (ou conjunto de partidos, no caso de coligação) está autorizado a apresentar apenas um candidato a prefeito.

\footnotetext{
${ }^{16}$ Antes da reforma constitucional de 1997, os partidos podiam apresentar um número ilimitado de nomes. A possibilidade da apresentação de candidaturas múltiplas e a contabilização de tais votos para o partido é centenária no país, tendo sido adotada em 1910. Conforme Buquet, Chasquetti e Moraes (1998), ela foi adotada para permitir que a divisão e a competição entre os grupos integrantes de um partido não se tornasse um prejuízo eleitoral e viesse a produzir cisôes, o que tem conseguido, pois ao longo desse período o Uruguai foi classificado como um sistema bipartidário ou de pluralismo limitado, seguindo as categorias formuladas por Sartori (1982).

${ }^{17} \mathrm{O}$ "Duplo voto simultâneo" é uma modalidade de voto preferencial intrapartidário ou de primárias que ocorrem concomitantemente à eleição. O eleitor vota primeiro no partido e depois, se este apresentar mais de um candidato, pode escolher um determinado concorrente (mas é possível votar apenas no partido, sem discriminar uma das candidaturas, o chamado "voto em lema", equivalente ao "voto na legenda" adotado no Brasil, nas disputas para deputado ou vereador). A eleição se decide por maioria simples, fica com a vaga o partido mais votado (os sufrágios obtidos pelos candidatos que cada partido apresentou contam primeiro para a legenda) e será considerado eleito o candidato mais votado da legenda mais votada. Logo, necessariamente não se elege aquele candidato que recebeu individualmente mais sufrágios. Na prática, há duas disputas simultâneas: entre os partidos e, em cada legenda, entre os candidatos que ela eventualmente apresentar. Para mais detalhes, ver em Buquet (2003).
} 
Tabela 6 - Resultado obtido na eleição seguinte pelo partido e pelo candidato que haviam conquistado o executivo local no Brasil e no Uruguai, no período 2000-2012 (\%)

\begin{tabular}{c|c|c}
\hline Situação & Brasil & Uruguai \\
\hline Ambos vitoriosos & 57,4 & 61,1 \\
\hline Ambos derrotados & 27,0 & 33,3 \\
\hline Partido vitorioso, incumbent derrotado & 4,7 & 5,6 \\
\hline Partido derrotado, incumbent vitorioso & 10,8 & - \\
\hline Total $(\mathrm{N})$ & 148 & 36 \\
\hline
\end{tabular}

Fonte: TSE-BR, Corte Electoral-UY (2010), Vários Autores (2000) e Buquet (2005a).

As informaçóes trazidas pela Tabela 6 mostram que, nos dois países, quando há incumbent envolvido na disputa, o resultado obtido pelo partido está intimamente relacionado a tal peculiaridade. No Brasil, em $84,4 \%$ dos casos o destino de um está vinculado ao do outro; no Uruguai, o índice chega a 94,4\%. Em termos específicos, ambos tiveram sucesso em $57,4 \%$ das disputas no primeiro e em $61,1 \%$, no segundo; e foram derrotados em $27 \%$ e em $33,3 \%$ dos casos, respectivamente. As diferenças existentes nesse quesito não são fortes o suficiente para alterarem as tendências, elas apenas permitem verificar que no Brasil ambos perdem e ganham menos intensamente do que no Uruguai.

As distinções mais marcantes surgem quando o resultado do partido é diferente daquele obtido pelo candidato à reeleição, pois, embora minoritárias e restritas a algumas poucas ocorrências, elas são reveladoras do papel desempenhado por partidos e por candidatos nos dois países.

O primeiro aspecto a destacar é que, no Brasil, em 10,8\% dos 148 pleitos analisados (16 ocorrências), o incumbent teve sucesso e o partido pelo qual ele havia se elegido originalmente foi derrotado. No Uruguai, essa situação não foi registrada até porque não há casos de intendentes que tenham trocado de partido ao longo do mandato ou de mudança de titular que implique também a do partido no governo ${ }^{18}$.

O segundo se refere ao cenário inverso, ou seja, quando o partido se manteve no poder e o incumbent foi derrotado. No Uruguai, em 5,6\% dos 36 pleitos analisados (dois casos), o titular do cargo perdeu a disputa interna e foi superado por um correligionário. No Brasil, o partido derrotou o incumbent em 4,7\% dos 120 pleitos considerados (sete casos). Como se percebe, houve mais do que o triplo de ocorrências no Brasil do que no Uruguai em número absoluto, embora em termos relativos seja este quem apresente o maior índice, e não aquele.

Esses dados apontam uma tendência bastante clara, contudo, também podem gerar uma percepção distorcida, pois não permitem distinguir se partido e incumbent

${ }^{18}$ Apesar de não registrada, teoricamente essa situação pode ocorrer. 
foram derrotados quando concorriam juntos e necessariamente obteriam o mesmo resultado ou quando eram adversários e poderiam ter destinos diferentes. Além disso, eles indicam simplesmente quantas vezes cada situação ocorreu, mas não a quantidade de oportunidades em que elas aconteceram quando era possível que os resultados eleitorais do partido e do incumbent fossem diferentes. Esta situação específica é apresentada pela Tabela 7 .

Tabela 7 - Resultado obtido na eleição seguinte pelo partido e pelo candidato que haviam conquistado o executivo local, quando estes podem apresentar resultados diferentes, no Brasil e no Uruguai, no período 2000-2012, em percentual

\begin{tabular}{c|c|c}
\hline Situação & Brasil & Uruguai \\
\hline Ambos vitoriosos & - & 54,8 \\
\hline Ambos derrotados & 8,0 & 38,7 \\
\hline Partido vitorioso, incumbent derrotado & 28,0 & 6,5 \\
\hline Partido derrotado, incumbent vitorioso & 64,0 & - \\
\hline Total (N) & 25 & 31 \\
\hline
\end{tabular}

Fonte: TSE-BR, Corte Electoral-UY (2010), Vários Autores (2000) e Buquet (2005a).

Antes de comentar os novos dados (Tabela 7), é preciso apresentar algumas ponderaçôes preliminares. A primeira alternativa (ambos reeleitos) só pode ocorrer no Uruguai, visto que o partido tem a prerrogativa de apresentar mais de um candidato, o que faz com que, sempre que a legenda fizer tal opção, o sucesso concomitante do partido e do incumbent seja um dos resultados que o pleito pode apresentar. No Brasil, como as regras exigem que o partido (ou a coligação) apresente somente um candidato, é impossível que ambos tenham sucesso se o destino eleitoral deles está dissociado. Em outros termos: se concorrem separados, apenas um pode ter sucesso; e o único resultado que eles podem compartilhar é o fracasso, plasmado pela alternativa "ambos derrotados".

$\mathrm{Na}$ mesma medida, e como já indicado anteriormente, embora teoricamente seja possível que um intendente uruguaio concorra à reeleiçẫo por um partido diferente daquele pelo qual se elegeu, isso não se verificou na prática, razão pela qual a alternativa "partido derrotado, incumbent vitorioso" só poderia ocorrer no Brasil.

Por fim, também como já foi exposto em momento precedente, a hipótese de vitória do partido e de derrota do incumbent é viável nos dois países, embora por motivações distintas.

Feitos esses esclarecimentos, observa-se pela Tabela 7 que, no Brasil, houve 25 casos em que os resultados do incumbent e do partido poderiam ser diferentes (16,9\% dos 148 pleitos em que o titular do cargo participa da disputa). Na ampla maioria deles (64\% ou 16 vezes) quem prevaleceu foi o candidato, e o partido que se 
consagrara nas urnas quatro anos antes amargou a derrota. Em 8\% (correspondentes a duas situações), ambos foram derrotados, ou seja, preponderou um terceiro competidor.

O partido conseguiu superar o antigo correligionário (na situação de troca de legenda) ou quem o substituiu (na de mudança do partido no poder) em $28 \%$ das eleiçóes (sete oportunidades). Porém, para reforçar o quadro de predomínio das lideranças frente às instituições partidárias, somente em três desses casos o partido preterido apresentou candidato próprio. Nas outras quatro oportunidades, ele compôs a coligação vencedora, a qual contava com um candidato apresentado por outro partido.

Embora a diferença em termos absolutos seja de apenas um caso, deve-se frisar que quando o partido que elegeu o prefeito tem de enfrentá-lo na tentativa de reeleição ou a quem o substituiu no cargo ao longo do mandato a opçáo preferencial foi lançar um candidato próprio (13 dos 25 casos) em relação a apoiar outro partido (12 situaçóes). Logo, o índice de sucesso da candidatura própria ao se defrontar com o incumbent é de $23 \%$ (três em 13) e o da opção de apoiar outro nome mostra-se bem mais elevado (33,3\% ou quatro em 12$)$.

Enfim, depois de perder o prefeito, a opção de se associar com um candidato eleitoralmente viável torna-se mais rentável (ou menos prejudicial, já que ambas registram percentuais minoritários de sucesso) do que a de lançar um candidato próprio. Embora ela não seja a situação preferencial, pois envolve ocupar posição de menor destaque do que quando apresenta a "cabeça de chapa", torna-se uma alternativa com vistas a alcançar novamente o poder, especialmente se o partido não possui em seus quadros alguém equivalente (em potencial eleitoral e em reconhecimento político) ao filiado que se elegera chefe do executivo ou a quem o substituiu durante o exercício do governo.

Cabe ponderar, ainda, que das três situaçóes em que o partido derrotou o incumbent com candidato próprio, em duas delas apresentou um ex-prefeito com experiência de dois mandatos, que se constituía em um dos principais líderes locais (Feira de Santana e Teresina, ambos em 2012). No terceiro caso (Campina Grande em 2004), a estratégia foi outra: atrair com a oferta da candidatura majoritária um quadro emergente pertencente à outra legenda.

Por fim, ressalva-se que das sete vezes em que derrotou o incumbent, em quatro delas este náo era o candidato eleito, e sim quem o substituiu ao longo do mandato e pleiteava a reeleição, o que pode ser indício da condição mais frágil de tais 
personagens, pois elas não foram eleitas diretamente para o cargo ${ }^{19}$. Aliás, isso também ocorreu em duas das três vitórias com candidatura própria obtida por partido que foi afastado do governo durante o mandato referenciadas acima.

No Uruguai, onde a apresentação de mais de um candidato é prática antiga e corrente $^{20}$, a possibilidade de partido e de incumbent alcançarem resultados distintos é muito mais ampla. Dos 36 pleitos que contaram com a presença do incumbent, em 31 deles $(86,1 \%)$ isso poderia ter acontecido, ou seja, o partido apresentou mais de um candidato. $\mathrm{Na}$ prática, essas possibilidades se mostraram residuais e se confirmaram em apenas dois casos, correspondentes a 6,5\%. Dito de outra forma: em $93,5 \%$ das situaçóes, os resultados que poderiam ser diferentes, foram idênticos. Para que se tenha uma ideia: no Brasil, em $92 \%$ das vezes em que os resultados desses dois atores poderiam ser diferentes, eles de fato o foram (23 em 25 oportunidades). Mais uma vez, há uma inversão quase coincidente entre os percentuais de cada país.

Dentre os fatores que podem explicar a pouca efetivação de resultados distintos entre partido e incumbent, Cardarello (2005 e 2009) arrola que a presença do intendente candidato à reeleição não evita que a legenda indique outro(s) candidato(s), mas tende a inibir que ele(s) seja(m) competitivo(s) e capaz(es) de efetivamente com ele disputar o primeiro lugar no partido (e provavelmente a vitória na eleição). $\mathrm{O}$ autor argumenta que, se isso acontecesse, haveria um acirramento da disputa interna que, em determinadas circunstâncias, poderia desgastar os candidatos e a própria legenda frente aos eleitores, favorecer concorrentes externos e levar ao fracasso. Em síntese: nesses casos, os partidos apresentam mais de um nome, mas a tendência é a de existir um único e claro candidato viável, o próprio incumbent.

A título de informação: 18 dos 31 incumbents que enfrentaram concorrência interna $(58,1 \%)$ obtiveram mais de $60 \%$ dos votos do partido, tenham ou não vencido o pleito. Outros nove conquistaram entre $50,1 \%$ a $59,9 \%$ dos votos. Logo, 27 dos $31(87,1 \%)$ intendentes candidatos à reeleição conquistaram a maioria absoluta dos votos do partido.

\footnotetext{
${ }^{19}$ No entanto, como são poucos casos, não há como confirmar tal tendência. Os dados relativos aos 24 casos de substituição presentes nesse estudo tampouco garantem tal condição, embora também apontem para a maior (mas não intensa) fragilidade deles em comparação ao conjunto dos elegíveis e dos concorrentes. Quem substituiu definitivamente o prefeito eleito concorre menos à reeleição (25\% não se reapresentaram frente a $18,2 \%$ no geral) e se elege menos $(66,6 \%$ frente a $68,1 \%$ no cômputo dos casos).

${ }^{20}$ Buquet (2005b, p. 19) anota que: "la candidatura única a la intendencia queda reducida a una situación marginal que se explica por situaciones particulares, pero la triple candidatura también tiende a ser excepcional por las dificultades de coordinación entre las fracciones partidarias que requiere”.
} 
Desse modo, os destinos do partido e do incumbent estão muito mais interrelacionados no Uruguai do que no Brasil. Como já mostrou a Tabela 7, em 54,8\% das vezes ambos venceram (17 ocasióes) e em 38,7\%, ambos perderam (12 ocasióes). Houve somente dois casos em que um concorrente interno superou o incumbent (correspondentes aos também já citados 6,5\%).

Mas é relevante comentar essas duas derrotas intrapartidárias do incumbent. A exemplo do caso brasileiro, Cardarello (2005 e 2009) pondera que a explicação para uma delas pode derivar do fato de o incumbent não ser o candidato eleito, e sim alguém que veio a assumir o cargo, o que faz com que ele possa ser politicamente frágil, razão pela qual é superado por outro correligionário, ainda mais se este tem uma importante trajetória política. Foi o que ocorreu no departamento de Lavalleja, na eleição de 2000: Giorello assumiu o cargo em 1997, em razão da morte do titular (Leis), o verdadeiro caudilho local. $\mathrm{Na}$ eleiçáo seguinte, ele acabou superado na disputa interna do Partido Nacional por Vergara, considerado o herdeiro político de Leis. Ainda assim, a disputa foi acirrada: o derrotado Giorello obteve 49,1\% dos votos do partido.

No outro caso, o de San José, também no pleito de 2000, o incumbent Cerdeña se defrontou com Chiruchi, que vinha a ser o antecessor dele e que só se afastara do cargo por ter cumprido dois mandatos consecutivos (havia sido eleito em 1984 e em 1989). Ou seja, apesar de ser o atual intendente, Cerdeña não era páreo para o grande nome do Partido Nacional no departamento, tão grande que, além de vencer o pleito de 2000, seria eleito para um quarto mandato em 2005.

Porém, como há pelo menos três casos de incumbents que nas mesmas situações de substituir o intendente originalmente eleito se reelegeram, não é possível generalizar tais afirmaçôes e ponderar que substitutos são institucionalmente mais frágeis, embora elas efetivamente possam explicar esses casos específicos.

\section{Conclusão}

O trabalho comparou a capacidade que apresentam dois atores políticos distintos, os titulares do cargo e os partidos, de se reeleger consecutivamente nas disputas para chefe do executivo subnacional do Brasil e do Uruguai (prefeito e intendente, respectivamente). Para isso acompanhou 305 eleições, realizadas no período 2000-2012, em 19 departamentos e em 62 municípios.

Os dados levantaram indicaram proximidade entre os dois países no que tange ao índice de prefeitos e de intendentes passíveis de concorrer à reeleição (na faixa dos $70 \%$ ) e que, tendo essa prerrogativa, de fato se reapresentaram ao eleitorado (no patamar dos $80 \%$ ), bem como obtiveram sucesso (na ordem dos $60 \%$ ). 
O mesmo cenário de equilíbrio não foi registrado, quando o percentual de reeleição é observado em relação aos partidos. As diferenças foram substanciais em favor das legendas uruguaias, que tiveram mais sucesso do que as brasileiras $(71,9 \%$ a $50,4 \%$ ), indício da maior importância delas em comparação ao candidato no país vizinho.

O cruzamento das informações relativas ao desempenho dos partidos quando podem ou não contar com o incumbent ajudou a consolidar tal diferença. $\mathrm{Na}$ oportunidade em que as legendas brasileiras e uruguaias possuem o candidato à reeleição, o índice de sucesso é semelhante (próximo a 70\%), mas quando o incumbent não se faz presente na disputa, os partidos brasileiros mantêm o cargo em apenas $32 \%$ dos casos contra $81 \%$ no Uruguai. Logo, pode-se dizer o êxito dos partidos uruguaios independe de ele contar ou não com o intendente que busca a reeleição imediata, ao inverso, eles apresentam índices mais intensos de sucesso quando não possuem o incumbent. $\mathrm{O}$ mesmo não ocorre no caso do Brasil, em que a reeleição do partido está intimamente relacionada ao fato de contar com o incumbent. Ou seja, o partido consegue se reeleger na maioria das vezes em que apresenta um candidato à reeleição, mas fracassa quando não tem tal personagem.

A ponderação das situações peculiares tanto de um país (migração partidária e troca de governante e de partido no poder, no Brasil) quanto do outro (candidaturas múltiplas no Uruguai) que permitem desassociar o destino do partido e do candidato reforça o maior peso do incumbent no Brasil e o das legendas no Uruguai. De um lado, essa possibilidade de dissociação se efetiva em cerca de $92 \%$ dos casos brasileiros e não se confirma em percentual muito semelhante dos casos uruguaios $(93,5 \%)$. De outro, quando esse confronto ocorre, prepondera o partido no Uruguai (duas vezes) e o candidato no Brasil (16 vitórias dele frente a sete da legenda).

No caso uruguaio, tais dados parecem corroborar larga bibliografia que destaca a importância dos partidos na estruturação da democracia daquele país, dimensionada a partir de diferentes critérios (SARTORI, 1982; GONZÁLEZ, 1991; MAINWARING e SCULLY, 1995; MAINWARING e BRINKS; PÉREZ-LIÑAN, 2001; MAINWARING e JONES, 2003; COPPEDGE, 2000), a qual foi sintetizada recentemente por Lanzaro (2013): 
[...] la expresión democracia de partidos (Parteiendemokratie, Party Democracy) es la más adecuada para definir el régimen uruguayo, se emparenta con la idea de 'república de partidos' o con la noción de party government y comporta un juicio positivo: una valoración acorde con las posturas que consideran a los partidos como actores imprescindibles de la democracia moderna, las cuales se abren camino desde principios del siglo XX y más nítidamente, a partir de los años 1940, después de las experiencias autoritarias precedentes (LANZARO, 2013, p. 236).

Por contraste, pode-se cogitar que o quadro brasileiro apresenta a preponderância dos candidatos em razão de os partidos não desempenharem frente ao eleitorado um papel tão decisivo quanto no Uruguai na hora de ele empreender suas escolhas relativas ao chefe do executivo municipal.

Alvaro Augusto de Borba Barreto é Professor do Programa de Pós-Graduação em Ciência Política da Universidade Federal de Pelotas. E-mail: albarret.sul@terra.com.br

\section{Referências}

BARRETO, Alvaro Augusto de Borba. A força do cargo: reeleição de prefeitos e intendentes no Brasil e no Uruguai (2000-2010). In: ALACIP - Congresso Latino-americano de Ciência Política, V, Buenos Aires, 2010.

- Descentralização político-administrativa: a experiência da criação de municípios no Uruguai (2009-2010). In: MENDONÇA, Daniel (Org.). Democracia e processos políticos. Pelotas: UFPel, 2011. p. 103-126.

. Eleiçóes municipais comparadas: a escolha do chefe do executivo no Brasil e no Uruguai e o impacto sobre os sistemas partidários locais (2000-2005). Revista Brasileira de Ciência Politica, Brasília, v. 7, p. 285-318, jan.-abr. 2012a.

. Instituiçôes subnacionais do Brasil e do Uruguai em análise comparada (2000-2010). In: ALACIP - Congresso Latinoamericano de Ciência Política, VI, Quito, 2012 b.

BUQUET, Daniel. El Doble voto simultáneo. Revista SAAP, Buenos Aires, v. 1, n. 2, p. 317-339, 2003.

BUQUET, Daniel (Coord.). Las claves del cambio: Ciclo electoral y Nuevo Gobierno 2004-2005. Montevideo: Ediciones de la Banda Oriental, 2005a.

BUQUET, Daniel. Elecciones Uruguayas 2004-2005: de la vieja oposición a la nueva mayoría. In: (Coord.). Las claves del cambio: Ciclo electoral y Nuevo Gobierno 2004-2005. Montevideo: Ediciones de la Banda Oriental, 2005b. p. 11-26. 
BUQUET, Daniel; CHASQUETTI, Daniel; MORAES, Juan Andres. Fragmentación politica y gobierno en Uruguay: ¿Un enfermo imaginário? Montevideo: Facultad de Ciencias Sociales, 1998.

CARDARELLO, Antonio. Entre la continuidad y la disidencia: perfiles de campaña en Maldonado, Paysandú, Salto y Colonia. In: LAURNAGA, María Elena (Coord.). La Geografía de un cambio: Política, gobierno y gestión municipal en Uruguay. Montevideo: Ediciones de la Banda Oriental, 2001. p. 73-88.

. Los intendentes y la elección inmediata. Los efectos probables y apreciados en 2005. In: BUQUET, Daniel (Coord.) Las claves del cambio: Ciclo electoral y Nuevo Gobierno 2004-2005. Montevideo: Ediciones de la Banda Oriental, 2005. p. 149-162.

. La Reelección inmediata del ejecutivo a nivel subnacional: Un estudio de tres casos. 2009. $243 \mathrm{f}$.

Tese (Doutorado em Ciência Política) - Programa de Pós Graduação em Ciência Política, Universidade Federal do Rio Grande do Sul, Porto Alegre, 2009.

CORTE ELECTORAL-UY. Corte Electoral del Uruguay. Elecciones departamentales y municipales 2010. Disponível em: <http://elecciones.corteelectoral.gub.uy/20100509/SSPMain.asp>. Acesso em: 18 set. 2012.

COPPEDGE, Michael. Partidos latinoamericanos: darwinismo político en la década perdida. Revista Argentina de Ciencia Política, n. 4, p. 113-146, 2000.

GONZÁLEZ, Luis E. Legislación electoral y sistema de partidos: el caso uruguayo. Revista Uruguaya de Ciencia Política, Montevideo, n. 4, p. 9-27, 1991.

GUERRINI, Aldo. El Peso político de los intendentes del interior: apuntes para una discusión a la luz de las últimas consultas electorales In: VÁRIOS AUTORES. Elecciones 1999-2000. Montevideo: Ediciones de la Banda Oriental, 2000. p. 185-193.

INE-UY. Instituto Nacional de Estadística del Uruguay. Censos 2011. Disponível em: <http://www.ine.gub.uy/censos2011/index.html>. Acesso em: 28 mar. 2014.

JONES, Mark. Electoral laws and the effective number of candidates in presidential elections. The Journal of Politics, University of Texas Press, v. 61, n. 1, p. 171-184, feb. 1999.

LANZARO, Jorge. Continuidad y cambios en una vieja democracia de partidos - Uruguay (19102010). Opiniáo Pública, Campinas, v. 19, n. 2, p. 235-269, nov. 2013.

LAURNAGA, María Elena; GUERRINI, Aldo. Del "buen vecino" al “intendente emprendedor": el rol de los intendentes departamentales en la reforma del Estado. Revista Uruguaya de Ciencia Política, Montevideo, n. 7, p. 83-97, 1994.

LÓPEZ, Santiago. ¿Cuán "locales” son las elecciones municipales en Uruguay? Estimando independencia de resultados y comportamientos electorales. Revista Uruguaya de Ciencia Política, Montevideo, n. 16, p. 73-101, 2007.

MAINWARING, Scott; SCULLY, Timothy (Eds.). Building democratic institutions: party systems in Latin America. Stanford: Stanford University Press, 1995.

MAINWARING, Scott; BRINKS, Daniel; PÉREZ-LIÑAN, Aníbal. Classificando regimes políticos na América Latina, 1945-1999. Dados: Rio de Janeiro, v. 44, n. 4, p. 45-687, 2001.

MAINWARING, Scott; JONES, Mark P. A Nacionalização dos partidos e dos sistemas partidários: uma mediação empírica e sua aplicação ao caso das Américas. In: TAVARES, José Antônio Giusti (Org.). O sistema partidário na consolidação da democracia brasileira. Brasília: Instituto Teotônio Vilela, 2003. p. 101-148.

OROÑO, Abel. Los Municipios en marcha: La descentralización local y los desafíos de su implementación. Montevideo: Friedrich Ebert, 2010. 
RODRIGUES, Fernando. 36\% dos eleitores estão em apenas 85 cidades. Blog do Fernando Rodrigues, 30 jul. 2012. Disponível em: <http://fernandorodrigues.blogosfera.uol.com.br/2012/07/30/brasiltera-eleicao-em-5-568-municipios-no-dia-7-de-outubro/>. Acesso em: 27 mar. 2014.

SARTORI, Giovanni. Partidos e sistemas partidários. Brasília: UnB, 1982.

TSE-BR. Tribunal Superior Eleitoral do Brasil. Eleiçóes anteriores (2012, 2008, 2004, 2000, 1996). Disponível em: <http://www.tse.jus.br/eleicoes/eleicoes-anteriores>. Acesso em: 26 mar. 2014.

VÁRIOS AUTORES. Elecciones 1999-2000. Montevideo: Banda Oriental; Instituto de Ciencia Política, 2000.

Texto recebido em 15 de setembro 2013. Aprovado em 25 de março de 2014. 
